\title{
Chemiluminescent Enzyme Immunoassay Using an Alkaline Phosphatase Label and an Indolyl Phosphate Substrate
}

\author{
Takashi Ikegami, Hidetoshi Arakawa, Masako MaEda and Akio TsujI \\ School of Pharmaceutical Sciences, Showa University, Hatanodai, Shinagawa, Tokyo 142, Japan
}

Keywords Chemiluminescence, indolyl phosphate, photon imaging, enzyme immunoassay, alkaline phosphatase

A non-isotopic immunoassay and a DNA probe assay have used enzymes, fluorescent dyes, europium chelates and chemiluminescent compounds as labels. Among these labels, enzymes are the most useful due to an amplifying effect. The sensitivity of enzyme label detection proceeds in the order: absorption < fluorescence $<$ chemiluminescence. The newer chemiluminescent methods can be used for detection with equal or greater sensitivity than radioisotopes.

Recently, chemiluminescent (CL) and bioluminescent (BL) detection methods for alkaline phosphatase (ALP) have been reported. An adamantyl 1,2-dioxethane phosphate (AMPPD) $)^{1}, \mathrm{NADP}^{+2}$ and firefly D-luciferin phosphate ${ }^{3}$ have been used as substrates for $\mathrm{CL}$ and $\mathrm{BL}$ assays of ALP.

More recently, we have developed a sensitive $C L$ assay of ALP using 5-bromo-4-chloro-3-indolyl phosphate $(\mathrm{BCIP})^{4}$ in which BCIP is enzymatically hydrolyzed to produce hydrogen peroxide $\left(\mathrm{H}_{2} \mathrm{O}_{2}\right) ; \mathrm{H}_{2} \mathrm{O}_{2}$ is detected by $\mathrm{CL}$ using isoluminol/microperoxidase (m-POD). ALP can be detected at a concentration of $7 \times 10^{-14} \mathrm{M}$ with this method, and it can be preliminarily applied to enzyme immunoassays (EIA) and DNA assays.

In this report, we examine the ability of indolyl derivatives, e.g. BCIP, 5-bromo-4-chloro-3-indolyl phosphate disodium salt (BCIP-2Na), 5-bromo-3-indolyl phosphate $p$-toluidine salt (BIP), 3 -indolyl phosphate $p$-toluidine salt (IP), 3-indolyl phosphate disodium salt (IP-2Na), as substrates for CL assays of ALP to obtain more sensitive assays. Among these indolyl derivatives, the $\mathrm{CL}$ assay of ALP using IP-2Na as a substrate was shown to be more sensitive than using other indolyl derivatives. This methods was applicable to CL EIA of alfa-feto protein (AFP). Moreover, the photon-imaging detection of ALP was developed by employing a modification of this assay system, in which ALP-catalyzed CL was constant for a prolonged period, and was applied to the EIA of a thyroid-stimulating hormone (TSH).

\section{Experimental}

\section{Materials}

Alkaline phosphatase (ALP, EC 3.1.3.1) was pur- chased from Boehringer Mannheim-Yamanouchi, Co. (Tokyo, Japan). Microperoxidase (m-POD) was obtained from Sigma Chemical Co. (St. Louis, USA). BCIP, BCIP-2Na, BIP, IP and IP-2Na were purchased from Wako Pure Chemical Industry Co. (Tokyo, Japan). Isoluminol was obtained from Tokyo Chemical Industry Co. (Tokyo, Japan).

An anti-AFP antibody-coated tube, an ALP-antiAFP antibody conjugate, an anti-TSH-antibody-coated plate and an ALP-anti-TSH antibody conjugate were donated by Sankyo Co., Ltd. (Tokyo, Japan).

Radioimmunoassay kits of AFP were purchased from Dainabot Co., Ltd. (Tokyo Japan).

Other chemicals were of analytical reagent grade.

\section{Apparatus}

The chemiluminescence intensity was measured by an Aloka Luminescence Reader.

Photon imaging detection was carried out using a Hamamatsu photonics ARGUS-50/MP.

\section{Procedures}

1. CL assay of ALP by a two-step method. A $10 \mu \mathrm{l} \mathrm{sam-}$ ple solution in a $0.1 \mathrm{M}$ Tris- $\mathrm{HCl}$ buffer (pH 9.5) containing $0.1 \%$ BSA was added to a microtest tube $(10 \times 75 \mathrm{~mm})$, followed by the addition of $100 \mu \mathrm{l}$ of a $0.38 \mathrm{mM}$ indolyl derivative solution in a $0.1 \mathrm{M}$ Tris- $\mathrm{HCl}$ buffer (pH 9.5) containing $0.1 \mathrm{M} \mathrm{MgCl}_{2}$. The reaction mixture was incubated at $37^{\circ} \mathrm{C}$ for $2 \mathrm{~h}$; then, $500 \mu \mathrm{l}$ of a $\mathrm{CL}$ reagent solution $\left(1.2 \times 10^{-4} \mathrm{M}\right.$ isoluminol and $5 \times 10^{-7}$ $\mathrm{M} \mathrm{m}-\mathrm{POD}$ in a $0.4 \mathrm{M}$ carbonate buffer ( $\mathrm{pH} 9.5)$ ) was added. The CL intensity was measured by an Aloka luminescence reader for a 6-s interval (from $15 \mathrm{~s}$ to $21 \mathrm{~s}$ ) after adding the $\mathrm{CL}$ reagent solution.

2. CL assay of ALP by a one-step method (photon-imaging detection). A $10 \mu \mathrm{l}$ sample solution in a $0.1 \mathrm{M}$ Tris- $\mathrm{HCl}$ buffer ( $\mathrm{pH} 9.5$ ) containing $0.1 \%$ BSA was added to a microtiter plate, followed by the addition of $200 \mu \mathrm{l}$ of a CL mixed solution of a substrate-CL reagent containing $2.5 \times 10^{-4} \mathrm{M}$ isoluminol, $5 \mathrm{U} / \mathrm{ml}$ horseradish peroxidase (HRP), $0.1 \mathrm{M} \mathrm{MgCl}_{2}$ and $0.19 \mathrm{mM}$ indolyl derivative in a $0.1 \mathrm{M}$ Tris-HCl buffer ( $\mathrm{pH}$ 9.5). The time course of the $\mathrm{CL}$ intensity was measured using a Hamamatsu Photo- 
nics ARGUS-50/MP for 15 min after adding a CL mixed solution of the substrate-CL reagent.

3. CLEIA of AFP. A $30 \mu l$ sample solution was added to the anti-AFP antibody-coated test tube, followed by the addition of $180 \mu \mathrm{l}$ of a $0.01 \mathrm{M}$ phosphate buffer $(\mathrm{pH}$ 7.0 ) containing $0.9 \% \mathrm{NaCl}$ and $0.1 \% \mathrm{BSA}$ (assay buffer). After incubating for $60 \mathrm{~min}$ at $37^{\circ} \mathrm{C}$, followed by washing the test tube three times with an assay buffer $(500 \mu \mathrm{l} \times 3)$, $300 \mu \mathrm{l}$ of the ALP-labeled mouse anti-AFP antibody was put into the test tube and incubated for $15 \mathrm{~min}$ at $37^{\circ} \mathrm{C}$.

After washing the test tube three times with the same buffer $(500 \mu \mathrm{l} \times 3), 200 \mu \mathrm{l}$ of a $0.38 \mathrm{mM}$ indolyl derivative was added and incubated for $15 \mathrm{~min}$ at $37^{\circ} \mathrm{C}$; then, $100 \mu \mathrm{l}$ of the reaction solution was added to a cuvette containing $200 \mu \mathrm{l}$ of the $\mathrm{CL}$ reagent solution described in procedure 1 , and the $\mathrm{CL}$ intensity was measured for $6 \mathrm{~s}$ using an Aloka luminescence reader.

4. CL EIA of TSH by photon-imaging detection. Each $25 \mu \mathrm{l}$ of human TSH standard solutions or serum samples were pipetted into an anti-TSH antibody-coated microtiter plate, followed by the addition of $75 \mu \mathrm{l}$ of an ALPlabeled anti-TSH antibody solution. After incubation for $2 \mathrm{~h}$ at room temperature, the microtiter plate was washed with a $0.05 \mathrm{M}$ phosphate buffer ( $\mathrm{pH} 7.0$ ) $(500 \mu \mathrm{l} \times 3)$. The time course of the $\mathrm{CL}$ intensity was measured using a Hamamatsu Photonics ARGUS-50/ MP for $15 \mathrm{~min}$ after adding $100 \mu \mathrm{l}$ of the $\mathrm{CL}$ mixed solution described in procedure 2.

\section{Results and Discussion}

We had previously developed CL assays of ALP, $\beta$-Dgalactosidase and $\beta$-glucosidase by using the $C L$ reaction after an enzymatic hydrolysis of indolyl derivatives. ${ }^{4}$ In this report we discuss the ability of various indolyl derivatives used as ALP substrates.

\section{Comparison of the CL intensities obtained by various indolyl derivatives}

BCIP was used as a substrate for a CL assay of ALP in a previous study. At present, several phosphates of indolyl derivatives are available as substrates for ALP. The CL intensities of these derivatives (BCIP, BCIP$2 \mathrm{Na}$, BIP, IP and IP-2Na), measured by procedure 1 , were compared at an ALP concentration of $1,10,100 \mathrm{pg} /$ àssay.

As shown in Table 1, the CL intensity of BIP was most weak, and sodium salt derivatives (BCIP-2Na and IP$2 \mathrm{Na}$ ) produced higher $\mathrm{CL}$ signals than those of $p$ toluidine salt derivatives (BCIP and IP). The differences in the $\mathrm{CL}$ of individual indolyl derivatives might be caused by differences in the hydrolysis rate. The indolyl derivatives having bromine and chlorine substituents are usually used for histochemical studies because of their high coloration and insolubility of the resulting products after an enzymatic reaction. On the other hand, the color of the reaction products of IP-2Na with ALP is more colorless than that of BCIP-2Na. Therefore, IP-
Table 1 Comparison of the intensity using various phosphates of indolyl derivatives as substrates of alkaline phosphatase

\begin{tabular}{lccrr}
\hline Substrate & 0 & 1 & \multicolumn{1}{c}{10} & $100 \mathrm{pg} /$ assay \\
\hline BCIP & 8 & $29(4)$ & $850(107)$ & $80100(10010)$ \\
BCIP-2Na & 7 & $37(5)$ & $1750(250)$ & $168900(24000)$ \\
BIP & 8 & $25(3)$ & $520(650)$ & $41600(5200)$ \\
IP & 8 & $23(3)$ & $690(86)$ & $42700(5340)$ \\
IP-2Na & 6 & $42(7)$ & $1840(306)$ & $142300(23710)$ \\
\hline
\end{tabular}

( ): $S / N$ ratio. BCIP: 5-bromo-4-chloro-3-indolyl phosphate $p$-toluidine salt $(0.38 \mathrm{mM})$; BCIP-2Na: 5-bromo-4chloro-3-indolyl phosphate disodium salt $(0.38 \mathrm{mM})$; BIP: 5-bromo-3-indolyl phosphate disodium salt $(0.38 \mathrm{mM})$; IP: 3-indolyl phosphate $p$-toluidine salt $(0.38 \mathrm{mM})$; IP-2Na: 3-indolyl phosphate disodium salt $(0.38 \mathrm{mM})$.

$2 \mathrm{Na}$ is preferable as a CL substrate for the assay of ALP.

\section{CL assay of ALP by a two-step method}

The CL assay of ALP by a two-step method using IP$2 \mathrm{Na}$ as a substrate was examined in order to establish the optimal conditions $(\mathrm{pH}$, reaction time and concentrations of the reagents used) determined, as described in procedure 1. As shown Fig. 1a, the working curve was obtained in the range of $3.5 \times 10^{-14} \mathrm{M}$ to $3.5 \times 10^{-11} \mathrm{M}$. The percentage of the relative standard deviation $(\mathrm{RSD} \%, n=5)$ at each point of the working curve ranged from 2.3 to $5.6 \%$, and the average was $4.0 \%$. The detection limit of the CL assay of ALP by the two-step method was $3.5 \times 10^{-14} \mathrm{M}$. This was determined by calculating the mean plus 2SD for 5 replicates of the zeroconcentration standard prepared from an assay buffer. The detection limit of two-step method using IP-2Na as a substrate was twice as sensitive as that using BCIP as a substrate.

\section{CL assay of ALP by a one-step method}

Recently, photographic detection has often been used for blotting assays. In these assays an antibody or an avidin-enzyme conjugate on a nitrocellulose filter is visualized by the addition of a light-emitting substrate (luminols or AMPPD ${ }^{6}$ ). The resulting light emission is detected by the use of either Polaroid film or X-ray film. In this detection system, it is preferable to use a $\mathrm{CL}$ reagent which provides a $C L$ glow signal, rather than a flash reaction. ALP-catalyzed CL from a AMPPD is in the form of a glow which persists for either decades of minutes. The enhanced $\mathrm{CL}$ of a horseradish peroxidase/luminol $/ \mathrm{H}_{2} \mathrm{O}_{2}$ reaction also provides a constant $\mathrm{CL}$ for a long time. Both systems are useful in blotting and sequencing assays. Therefore, a one-step method using IP-2Na was examined in order to establish the optimal conditions, which are described in procedure 2. The CL generated from the one-step method was constant for a period of time. After photon counting using a Hamamatsu Photonics ARGUS-50/MP, spots of standard solutions in a microtiter plate were obtained. 

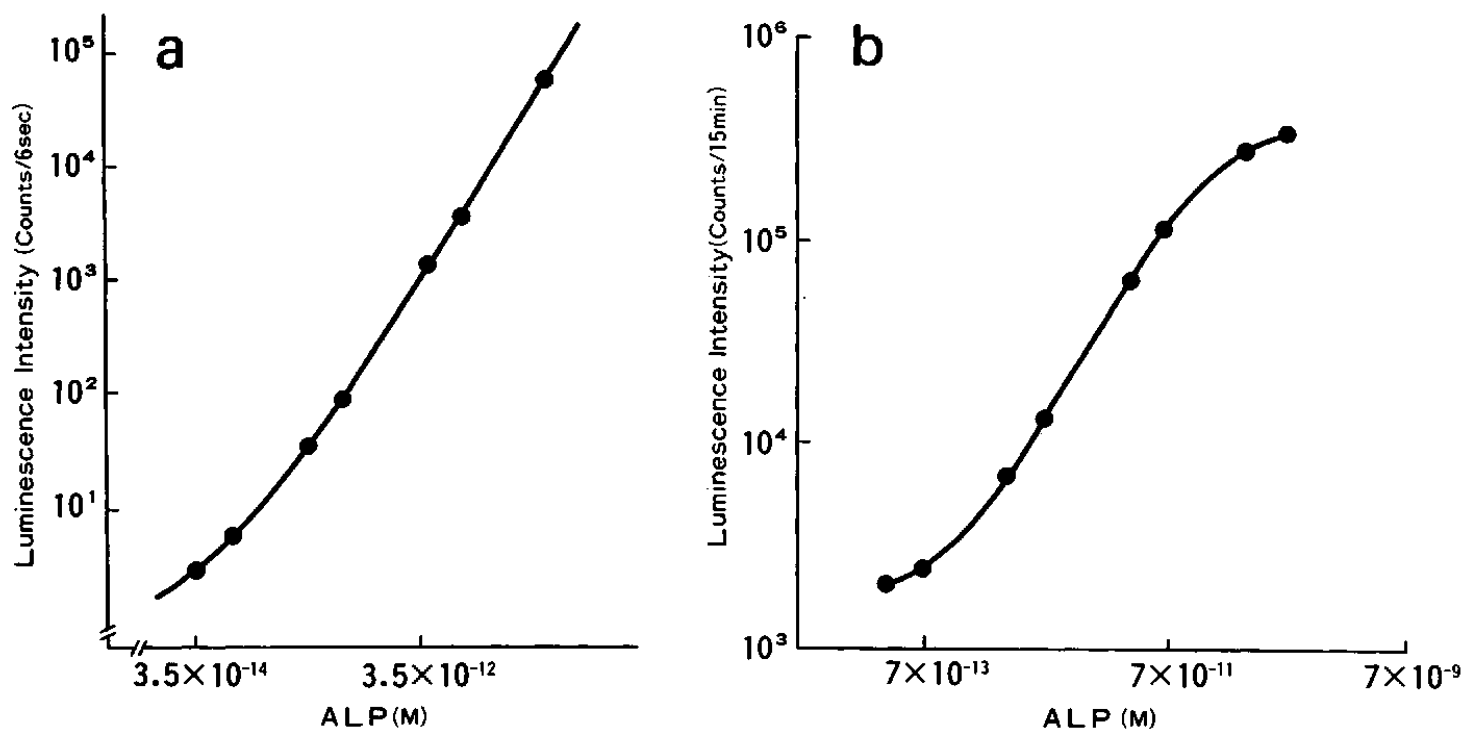

Fig. 1 (a) Standard curve of ALP by the 2-step method. method (photon-imaging method).

(b) Standard curve of ALP by the 1-step

As shown in Fig.1b, a working curve was obtained in the range of $3.5 \times 10^{-13} \mathrm{M}$ to $3.5 \times 10^{-10} \mathrm{M}$. The RSD\% $(n=5)$ ranged from 1.2 to $9.3 \%$, and the average was $5.8 \%$. The lower detection limit in the one-step method was $7 \times 10^{-13} \mathrm{M}$, which was determined by calculating the mean plus 2SD for 6 replicates of a zero-concentration standard solution. This detection limit is one tenth as sensitive as that obtained by the two-step method.

\section{Application of a two-step CL assay of ALP in the AFP immunoassay}

A two-step CL assay of ALP using IP-2Na as a substrate can be used to detect alkaline phosphatase conjugate in EIA. A sandwich-type EIA for AFP was developed. Two monoclonal antibodies were used in the assay. One was labeled with ALP by Ishikawa's method; ${ }^{7}$ the other one was coated on a polystyrene tube. Various factors were examined to establish the optimal standard method of EIA for AFP. The procedure was determined as described in procedure 3 .

Figure 2 shows a typical working curve of AFP obtained by a two-step method. The measurable range of AFP was 0.5 to $1000 \mathrm{ng} / \mathrm{ml}$. The detection limit of AFP by this method was $0.5 \mathrm{ng} / \mathrm{ml}(S / N=2)$. The sensitivity of this EIA with IP-2Na as a substrate is twotimes higher than that of the previous method using BCIP as well as the sensitivity of ALP assay. An intra assay RSD\% $(n=5)$ ranged from 3.0 to $5.0 \%$, with an average of $3.8 \%$. To assess the reliability of this proposed method, the AFP concentrations of serum samples $(n=93)$ were determined by the CL EIA method and by a commercial radioimmunoassay (RIA) kit (ABBOT Co.).

The results obtained by the proposed CL EIA method correlated well with those from the RIA kit. The correlation coefficient between these two methods was

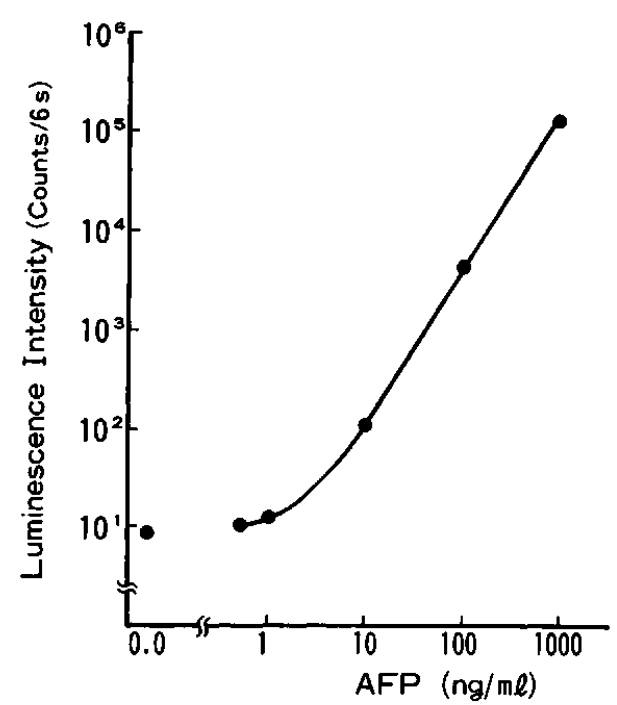

Fig. 2 Standard curve of AFP by the 2-step method.

0.996, the slope 1.05, and the Y-intercept 6.50. This method is reproducible and accurate, and should be useful for routine assays.

Application of the one-step CL assay of ALP in the TSH immunoassay

The one-step CL assay of ALP using IP-2Na as a substrate can be used to detect an ALP conjugate in EIA. A sandwich-type ELISA for TSH was developed. The anti-intact TSH antibody was labeled with ALP by Ishikawa's method; ${ }^{7}$ the other one, an anti-beta subunit TSH antibody was coated on a polystyrene titerplate well. Various factors were examined to establish the optimal conditions of EIA for TSH. The procedure of 


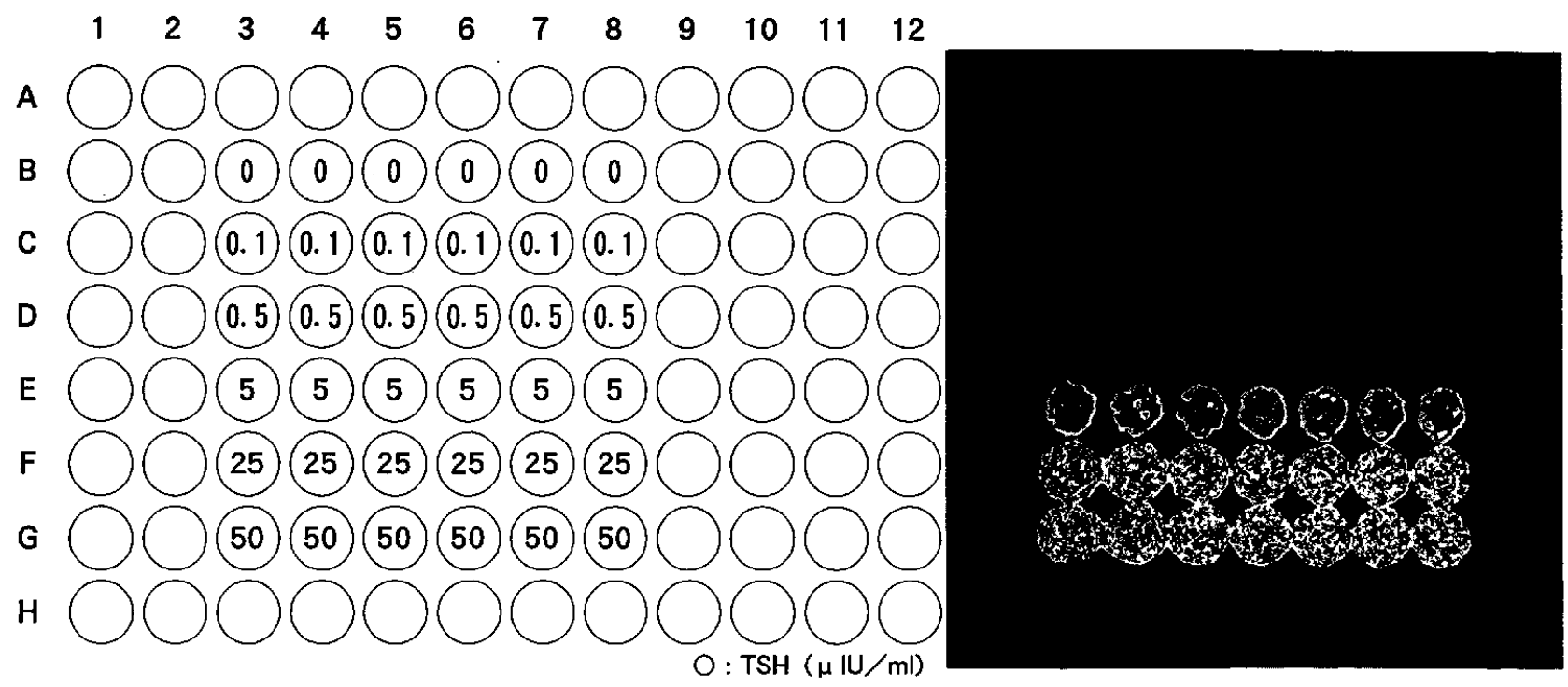

Fig. 3 Photon imaging of the TSH assay.

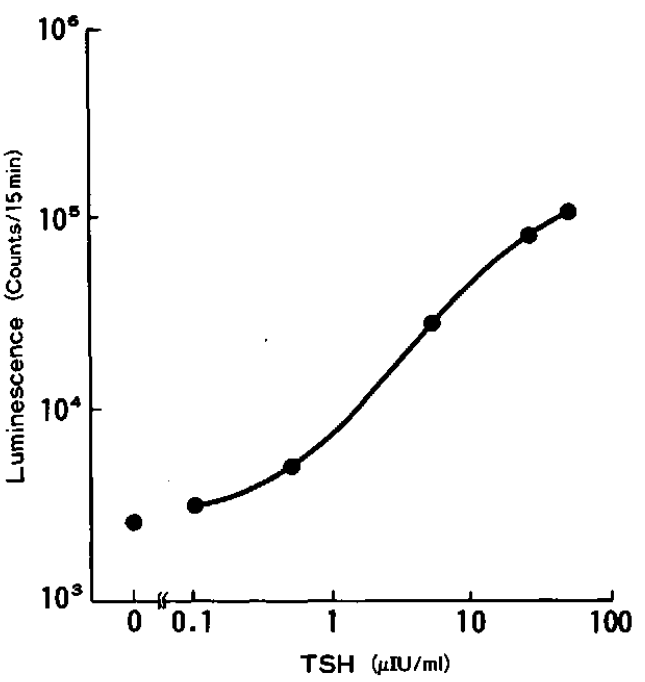

Fig. 4 Standard curve of TSH by the 1-step method (photonimaging method).

the ELISA system was determined as described in procedure 4. In this assay, a photographic imaging system using a Hamamatsu Photonics ARGUS-50/MP was applied. The measurable range of TSH was 0.1 to $50 \mu \mathrm{IU} / \mathrm{ml}$. The lower detection limit of TSH was $0.05 \mu \mathrm{IU} / \mathrm{ml}$, determined by calculating the mean plus 2SD for 6 replicates of the zero concentration standard prepared from serum. Figure 3 shows the obtained photon-imaging of the TSH assay. Figure 4 shows a typical working curve of TSH obtained by the one-step method. An intra assay RSD\% $(n=6)$ was $4.9 \%$ at $1.0 \mu \mathrm{IU} / \mathrm{ml}$. This assay is both simple and versatile. In addition, its sensitivity is sufficient to be applied to the diagnosis of thyroid functions.
In conclusion, we examined the ability of various indolyl derivatives in the CL assay of ALP and IP sodium salts showing the best results. By using IP sodium salts, we could detect as little as $3.5 \times 10^{-14} \mathrm{M}$ ALP. This is twice as sensitive as the previously reported assay using BCIP-2Na. In addition, we developed a one-step ALP assay using IP as a substrate. The one-step method could be utilized for photo imaging, because light emission from the one-step method lasts for at least $30 \mathrm{~min}$. Though the detection limit obtained by this assays is less than that by a two-step assay, the one-step method is simpler.

With the two ALP assays described above, we developed highly sensitive enzyme immunoassays of AFP and TSH.

\section{References}

1. I. Bronstein, B. Edwards and C. Voyta, J. Biolumin. Chemilumin., 4, 99 (1989).

2. H. Arakawa, M. Maeda, A. Tsuji and T. Takahashi, Chem. Pham. Bull., 37, 1831 (1989).

3. W. Miska and R. Geiger, J. Clin. Chem. Clin. Biochem., 25, 23 (1987).

4. H. Arakawa, M. Maeda and A. Tsuji, Anal. Biochem., 199, 238 (1991).

5. M. M. L. Leong and G. R. Fox, Anal. Biochem., 172, 145 (1988).

6. I. Bronstein, C. Voyta. John and B. Edwards, Anal. Biochem., 180, 95 (1989).

7. E. Ishikawa, M. Imagawa, S. Hashida, S. Yoshitake, Y. Hamaguchi and T. Ueno J. Immunoassay, 4, 209 (1983).

(Received May 23, 1994) (Accepted July 11, 1994) 